\title{
A multipurpose X-ray fluorescence scanner developed for in situ analysis
}

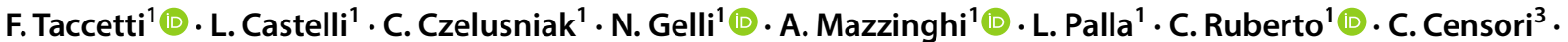

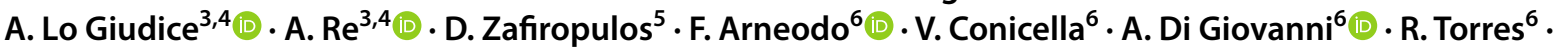 \\ F. Castella ${ }^{7} \cdot$ N. Mastrangelo ${ }^{7} \cdot$ D. Gallegos ${ }^{7} \cdot$ M. Tascon $^{7}$ (D) $\cdot$ F. Marte $^{7} \cdot$ L. Giuntini $^{1,2}$
}

Received: 9 November 2018 / Accepted: 10 December 2018

(c) Accademia Nazionale dei Lincei 2019

\begin{abstract}
Over the time, instrument transportability has become more and more important, especially in Cultural Heritage, as often artworks cannot be moved from their site, either because of the size or due to problems with permission issues, or simply because moving them to a laboratory is physically impossible, as e.g. in the case of mural paintings. For this reason, the INFN-CHNet, the network for Cultural Heritage studies of the Italian National Institute of Nuclear Physics (INFN), has developed an XRF scanner for in situ analyses. The instrument is the result of a wide collaboration, where different units of the network have been developing the diverse parts, then merged in a single system. The XRF scanner has been designed to be a four-season and green instrument. The control/acquisition/analysis software has been fully developed by our group, using only open-source software. Other strong points of the system are easiness of use, high portability, good performances and ultra-low radiation dispersion, which allows us to use even when the public can be present. It can run both with mains or on batteries, in the latter case with a maximum runtime longer than $10 \mathrm{~h}$. It has a very low cost, when compared to commercial systems with equivalent performances, and easily replaceable components, which makes it accessible for a much wider portion of the interested community. The system has been thought and designed as an open system, suitable for further development/improvements, that can result interesting for non-conventional XRF analysis. The CHNet XRF scanner has proved to be really very well suited for applications in the Cultural Heritage field, as testified by the many recent applications. This paper describes the present version of our instrument and reports on the tests performed to characterise its main features.
\end{abstract}

\section{Graphical abstract}

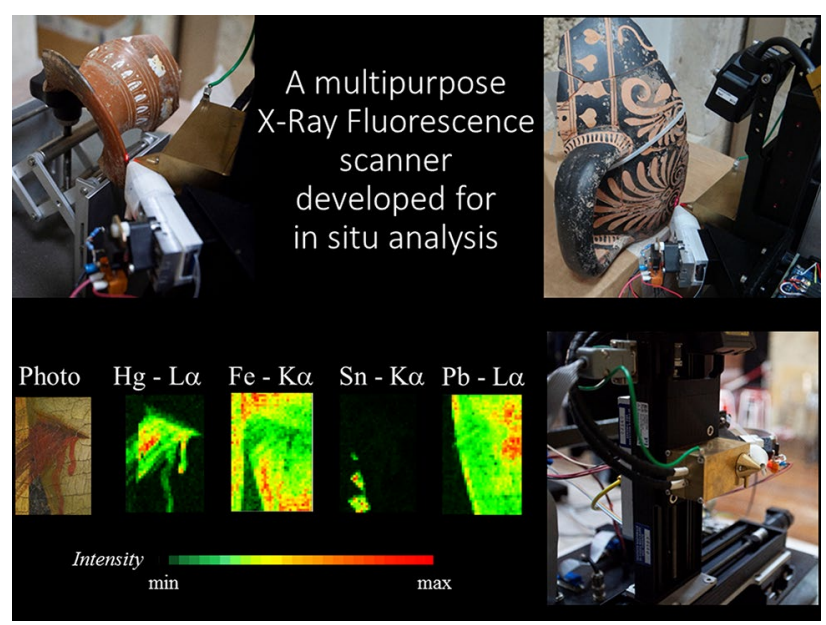

Keywords XRF scanner $\cdot$ Acquisition $\cdot$ Transportable instrument $\cdot$ XRF imaging $\cdot$ Cultural heritage $\cdot$ In situ analysis

Extended author information available on the last page of the article 


\section{Introduction}

Over the time, instrument transportability has become more and more important in Cultural Heritage (CH) [(Dal Bianco and Russo 2012); (Mendoza Mendoza and Gravie 2011); (Alfeld et al. 2013a, b); (Charlton 2013); (Duran et al. 2014); (Robinson et al. 2015); (Santos et al. 2016); (Ricciardi et al. 2016); (Romano et al. 2016, 2017); (Alfeld and de Viguerie 2017); (Holakooei et al. 2017); (De Keyser et al. 2017); (Van der Snickt et al. 2017); (Hoffmann et al. 2018); (Legrand et al. 2018); (Van der Snickt et al. 2018)] and in other fields [(Elisabeth et al. 2011); (Ryan et al. 2017); (Theden-Ringl and Gadd 2017); (Lemière 2018); (Profe et al. 2018)], as often artworks cannot be moved from their site, either because of the size or due to problems with permission issues, or simply because moving them to a laboratory is physically impossible, e.g. in the case of mural paintings.

For this reason, the INFN-CHNet, the network for Cultural Heritage studies of the Italian National Institute of Nuclear Physics (INFN), has developed an XRF scanner for in situ analyses; the instrument is the result of a wide collaboration, where different units of the network have been developing the diverse parts, then merged in a single system.

The instrument described in this paper has been designed to be a four-season and green instrument. The control/acquisition/analysis software has been fully developed by our group using open source software only. Other strong points are easiness of use, high portability (low weight and dimensions), good performances, when compared to commercial instruments, and ultra-low radiation dispersion, which allows us to use the system even when the public can be present. It can run both with mains or on batteries, in the latter case with a maximum runtime longer than $10 \mathrm{~h}$. It has a very low cost, when compared to commercial systems with equivalent performances, and easily replaceable components, which makes it accessible for a much wider portion of the interested community. The system has been thought and designed as an open system, easy to integrate with further development/improvements, that can result interesting for non-conventional XRF analysis.

This XRF scanner has proved to be really very well suited for applications in the Cultural Heritage field, as testified by the many recent applications, some of which are already published [(Macková 2016); Ruberto et al. 2016); (Lazic et al. 2018); (Striova et al. 2018)] and many more still unpublished. Due to its effectiveness, we presently have a fleet of five equivalent instruments, distributed in the INFNCHNet laboratories, ready to move wherever XRF in situ analyses are needed.

This paper describes the present version of our instrument and reports on the tests performed to characterise its main features.

\subsection{The main elements composing the XRF scanner}

The INFN-CHNet network XRF scanner, shown in Fig. 1, is a complete, independent system, composed by many subsystems, the most important of which are described in the following.

\subsubsection{X-ray tube}

The X-ray beam is generated by a small $\left(30 \times 30 \times 60 \mathrm{~mm}^{3}\right)$ Moxtek MAGNUM ${ }^{\circledR}$ X-ray tube $(127 \mu \mathrm{m}$ Be exit window,
Fig. 1 The most recent version of the CHNet-INFN scanner, with the batteries connected. The brass piece is the case of the X-ray tube, $4 \mathrm{~mm}$ thick, which cuts down to background level the radiation emitted backwards, equipped with a brass cone holding the collimator. Also visible the pipes for helium, both along the primary and secondary X-ray paths, the detector assembly (in the white plastic cone), the telemeter unit (above the brass box) and the three motorised axes (see text for details)

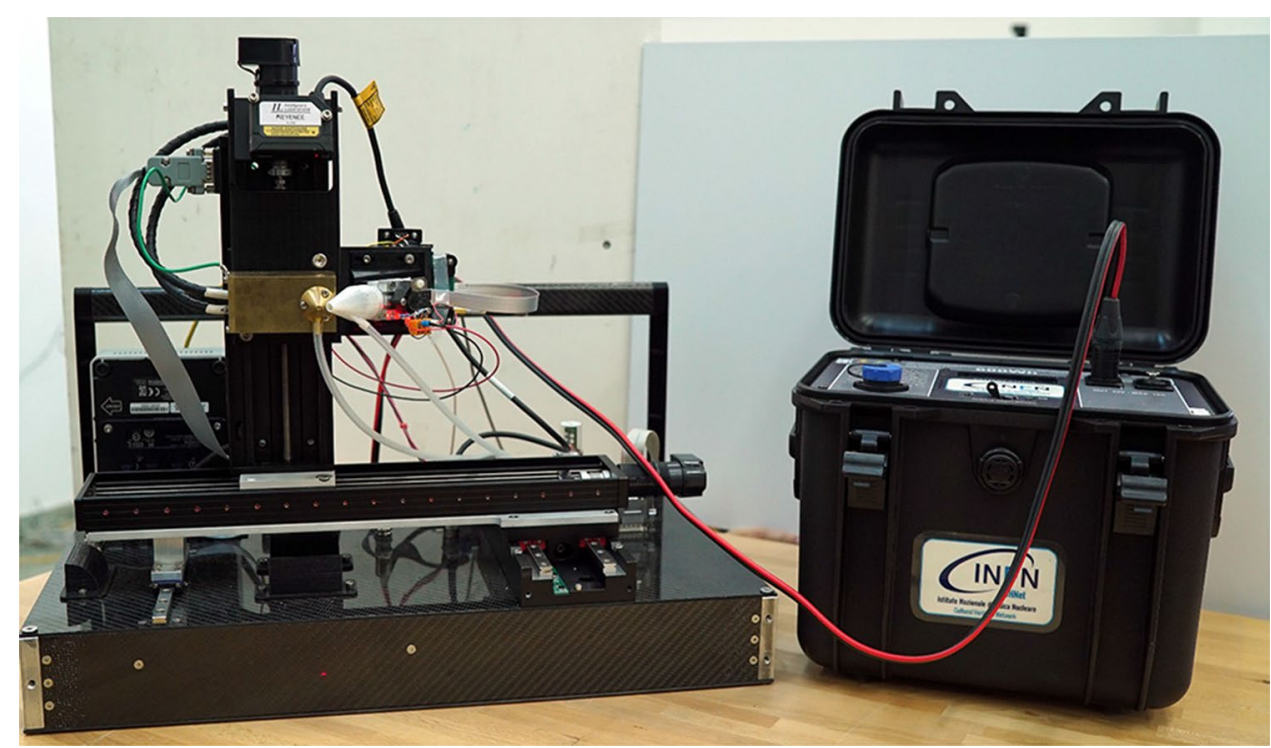


$40 \mathrm{kV}$ maximum voltage and $0.1 \mathrm{~mA}$ maximum anode current) (Moxtek 2018), powered by a compact $(130 \times 50 \times$ $20 \mathrm{~mm}^{3}$ ) power supply (PS) which controls both filament current and accelerating voltage. The PS is located a few centimeters behind the X-ray tube. The whole system weighs only $450 \mathrm{~g}$ and absorbs $8 \mathrm{~W}$.

Typical beams produced by these tubes have about $300 \mu \mathrm{m}$ spot sizes and $40^{\circ}$ divergence, as reported in the specification file; beam dimensions are defined by interchangeable collimators (from $1 \mathrm{~mm}$ down to $0.1 \mathrm{~mm}$, in $0.1 \mathrm{~mm}$ step, being $0.8 \mathrm{~mm}$ the most typical choice) at a sample-to-collimator distance of about $5.5 \mathrm{~mm}$ (hereafter, called "working distance"). Beam dimension characterisation for the $0.8 \mathrm{~mm}$ collimator is reported in Sect. 3.4.

Depending on the applications, it is possible to choose $\mathrm{Cr}$, $\mathrm{Cu}$ or Mo anodes, to maximize the measurement sensitivity [see for example (Migliori et al. 2011), where our previous XRF instrument is presented, for a comparison of the efficiencies using different anodes]. The tube is enclosed inside a 4-mm thick brass case, a thickness sufficient to reduce the transmitted radiation down to the background level (see Sect. 3.7 for details).

\subsubsection{Detector}

The detector presently adopted for the XRF scanners is the low-cost silicon drift detectors Amptek XR100 SDD, $70 \mathrm{~mm}^{2}$ active area, collimated to $50 \mathrm{~mm}^{2}$, and $500 \mu \mathrm{m}$ thick, $130 \mathrm{~g}$ weight and $2 \mathrm{~W}$ absorbed power (Amptek 2018). When the sample is at the working distance, the $12.5 \mu \mathrm{m}$ thick Be entrance window is at $\sim 25 \mathrm{~mm}$ from the beam impact point on sample. The detector is at $45^{\circ}$ with respect to the X-ray beam direction, the beam being horizontal and the sample vertical.

The detector is powered by the remotely-controlled highvoltage output of the digitizer (see below) via a custom electronic board, designed inside INFN-CHNet, which allows filtering low voltages and bias.

\subsubsection{Acquisition electronics}

The scanner is equipped with a compact desktop CAEN digitizer (100 MS/s, 14-bit), which will allow in the next future developing multi-detector instruments. In the present single detector configuration, we typically use the DT5780 (Caen 2018), which integrates two independent $16 \mathrm{k}$ Digital MCA. These digitizers provide detector high voltage and bias and are able to directly handle the signals coming from the charge sensitive preamplifiers of the SDD detectors. The input stage of the digitiser has been modified to optimise the treatment of the signals from the detector.

These digitisers allow for high-rate data transfer toward the control computer, via optical link, as they can feature bandwidths up to $100 \mathrm{MB} / \mathrm{s}$, by far greater than usual acquisition rates. Further appealing features of these digitizers for portable instruments are the very low weight $(<1 \mathrm{~kg})$ and power consumption $(<45 \mathrm{~W})$.

\subsubsection{Motion}

We assume that the XY plane is parallel to the sample surface (vertical) and that the $Z$ axis is horizontal and perpendicular to the sample surface. In this way, the motion in the $X Y$ plane allows us to scan the sample surface, while the motion along the $Z$ axis allows for adjusting the sample-toscanner distance (see next Sect. 1.5 Autofocus for details).

Motion is carried out by exploiting three linear stages (DC-current M404.8PD or VT80, both by Physik Instrumente (PI 2018a, b), depending on the application). These stages offer low weight $(\sim 2.5 \mathrm{~kg}$ and $\sim 1 \mathrm{~kg}$, respectively), high load ( $\max 200$ and $50 \mathrm{~N}$ ), high-precision (few microns and $20 \mu \mathrm{m}$ overall position uncertainty, respectively) very small minimum incremental motion (less than $1 \mu \mathrm{m}$ for both stages) and fast load motion (up to $50 \mathrm{~mm} / \mathrm{s}$ and $20 \mathrm{~mm} / \mathrm{s}$, respectively).

The travel ranges available for the $X$ and $Y$ axis are: 200, 300 and $600 \mathrm{~mm}$, while for the $Z$ axis we can choose between 50,100 and $200 \mathrm{~mm}$, being the $300(X) \times 200(Y) \times 50(Z)$ $\mathrm{mm}$ the most typical choice.

For all the stages, load motion is actuated via PI Mercury TM/C-862 DC controllers (no aluminium case, just the board, with an overall weight less than $0.1 \mathrm{~kg}$ ). The power consumption is less than $30 \mathrm{~W}$. All the controllers are USB connected to the control computer.

\subsubsection{Autofocus}

In $\mathrm{CH}$ field it is frequent to find artworks with non-flat surface, which can cause modifications of the irradiation and detection geometries and make the analysis unreliable or even impossible. To overcome this limitation, our XRF scanner are equipped with a dynamic positioning system based on a laser telemetry sensor, directly connected to the $\mathrm{Z}$ motorised stage. The position signal provided by the telemeter is used to automatically keep the scanner-to-specimen distance constant during the measurements, thus avoiding the aforementioned problems.

The autofocus system is composed of a lightweight (130 g) CMOS laser sensor (Keyence IA-100), an amplifier unit (Keyence IA-1000) (Keyence 2018) and an Arduino ADC control board, USB connected to the control PC. The sensor unit is mounted on the measuring head, in such a way that the sample-to-sensor distance is $\sim 10 \mathrm{~cm}$ when the scanner is at the working distance from the sample; in this configuration, the laser spot and the X-ray beam coincide on the sample surface. The sensor triangulates a laser beam 
(655 nm emission wavelength) to measure the distance to the target, with an overall error less than $10 \mu \mathrm{m}$. The signal output from the sensor is channeled to the amplifier unit, whose signal is fed to the Arduino board for analog-digital conversion. Thanks to the internal calibration, this is transformed into the measured sample-to-scanner distance. This value is compared with the set value and the scanner position is adjusted consequently by changing the $Z$-axis position.

\subsubsection{Helium flow controller}

In our XRF scanner, great care has been dedicated to lowenergy X-ray detection, as it may be crucial in many application (e.g. characterisation of lapis lazuli). Very good detection efficiency for low-energy X-rays has been achieved using of He-enriched atmosphere in between sample and detector and between sample and X-ray tube. Helium is conveyed from a gas bottle to a plastic nozzle installed on the top of the detector. Helium fills the volume of the plastic nozzle in front of the detector entrance window and then flows outwards. In this way, low-energy X-ray absorption is strongly reduced and this allows for detecting X-rays down to $\mathrm{Na}(\sim 1 \mathrm{keV})$ (see Sect. 3.2 detection efficiency).

He flow is controlled by an Alicat MC Mass Flow Controller ( $0-5 \mathrm{slpm}$ full scale, $0.5 \mathrm{~kg}$ weight), which allows us to set the desired flow in any value ranging from 0 up to 5 slpm, being 2 slpm the typical choice.

\subsubsection{Radio-safety}

XRF scanners can be equipped with two systems to create a $2 \times 2 \mathrm{~m}^{2}$ no-access area, based on photoelectric or ultrasonic sensors, depending on applications and environmental conditions. The former is based on four independent, light and easy-to-move fence posts (some kg), equipped with Sick/ W14 photoelectric sensors and reflectors, which define the no-access area. This system is heavier than the other one but less sensitive to environmental conditions (such as for example, dust dispersed in the air). The latter exploits four HC-SR04 ultrasonic sensors (maximum allowable distance of $4 \mathrm{~m}$ for the linear dimensions of the no-access area, thus more than what is required), integrated in a single device installed directly on the scanner, without cablings and thus allowing to further reducing weight and dimensions (total weight less than $0.1 \mathrm{~kg}$ ).

Independently on the chosen system, a $2 \times 2 \mathrm{~m}^{2}$ no-access area is defined, which, if accessed, causes the switch off of the X-ray source.

The system works as follows: when the X-ray tube is switched on, a red light switches on as well. An emergency button installed inside the no-access area allows to manually turn off the tube PS in case of emergency and thus to stop the $\mathrm{X}$-ray emission. If the signal from any sensor is intercepted (e.g. if someone enters the no-access area), the interlock system turns off the PS of the X-ray tube. In this condition, the PS can be re-switched on only after the clearance of the area. Clearance can be actuated if and only if ALL the following conditions are simultaneously met:

- All interlock switches must be closed (i.e. all the cell signal must not be intercepted).

- The emergency stop button is in the "released" position.

- The interlock reset button in the control computer, which is out of the no-access area, has been activated.

\subsubsection{Batteries}

To make the XRF scanner usable wherever the work of art is conserved, it is necessary to take into consideration also those cases where no mains is available. We have fully understood the importance of such a feature during measurements on frescos in archeological sites where no plug power was available.

To overcome this problem and to avoid the need of heavy and cumbersome motor generators, the scanner voltage distribution is based on a AC-DC converter, where the 220 VAC are converted to 24 VDC, which are then used directly or further transformed to $+15,-15,+12$ and $+5 \mathrm{VDC}$ to power all the internal devices. In this way, we can directly connect the 24 VDC batteries to the output of the AC-DC converter and run the system on batteries instead of using the mains. We have two batteries, which can provide $50 \mathrm{Ah}$ and $25 \mathrm{Ah}$, respectively. They have been designed for a $5 \mathrm{~A}$ use, which corresponds to $10 \mathrm{~h}$ ( $5 \mathrm{~h}$ for the smaller version) time of continuous usage with a weight of $10 \mathrm{~kg}(6 \mathrm{~kg})$. Measurements have shown a power consumption in normal conditions $10-20 \%$ lower than the design value, thus the system can run on batteries for a whole working day. The time required for a full charge is few hours.

\section{Summary of the XRF scanner}

The measuring head, composed of the X-ray tube +PS, the $\mathrm{X}$-ray detector + preamplifier, a TV camera (Ethernet controlled), is supported by the $\mathrm{X}-\mathrm{Y}-\mathrm{Z}$ linear stage assembly described above. The lower plate of the $\mathrm{Z}$ stage is screwed on the top of a carbon fiber box $\left(70 \times 50 \times 5 \mathrm{~cm}^{3}\right)$, which contains the digitizer and all the ancillary elements of the scanner (power supplies of the motors, detectors, telemeter, camera, USB hub, digitizer, cooling fans, ....). Supports, pillars and holders of many parts have been 3D printed, using PLA or ABS and can be easily replaced/modified in-house, if necessary for successive instrument customisation.

The hardware of the scanner has been designed and built paying the highest attention to dimensions, power and 
weight minimisation. The whole system, composed of the scanner, the control computer and the radioprotection system, weighs less than $10 \mathrm{~kg}$ (less than $20 \mathrm{~kg}$ including batteries) and can be easily transported by only one person in three light boxes. This small volume equipment is easily transported using a small city-car. The total absorbed power is less than $100 \mathrm{~W}$ (see Sect. 3.5).

\subsection{Software}

The control/acquisition/analysis software have been entirely developed by our group using only open source software, an approach followed only in a few cases [(Wegrzynek et al. 2005); (Bogovac et al. 2009); (Wrobel et al. 2012, 2016)] but which is nonetheless very fruitful because it allows to have a flexible system, easy to tailor to diverse experimental configurations and open to further developments. The instrument can be used for point and imaging XRF analysis. To map the area to be investigated, an in-house software has been developed using the Qt Platform, a cross-platform application development framework (QT 2018).

The software fully controls the scanner peripherals (motors, DAQ, autofocus, etc.) and provides additional tools for data analysis and map creation (e.g. spatial distribution of any element or energy region of interest and also of RGB maps, which mix in a single image the pieces of information arising from three different, user-defined elements).

The maximum size of a single map in the typical scanner configuration is $30 \times 20 \mathrm{~cm}^{2}$, limited only by the range of the motorized stages (see Sect. 1.4 for details). Maps are built by moving the scanner at a constant speed over every row (alternatively, on every column) and moving the measurement head to the next row (column) when the end of the row (column) is reached. Counts in the parts where the speed does not stay constant (i.e. at the beginning and at the end of every line), although acquired, are not taken into

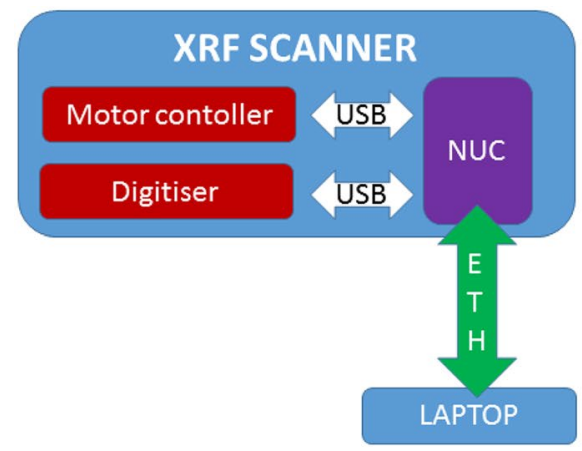

Fig. 2 Scheme of the two available types of data acquisition. The in situ DAQ-mode is based on an on-board NUC PC, USB connected to the digitiser. The NUC is Ethernet (or wireless) controlled by a laptop via a SSH connection, thus making possible to remotely consideration for map construction because the geometrical correctness of X-ray maps, i.e. their correspondence with the optical image, relays on the constancy of the scanning speed.

The XRF scanner has been thought to run using two different types of data acquisition, depending on its use (i.e. in lab or for in situ analysis), as illustrated in Fig. 2.

The in situ DAQ-mode (i.e. for measurements out of the lab) is based on an on-board PC $(10 \mathrm{~cm} \times 10 \mathrm{~cm}$ mini PC Intel NUC, $0.5 \mathrm{~kg}$ weight), interfaced to the digitiser via a USB 2.0 connection, which allows data transfers up to $30 \mathrm{MB} / \mathrm{s}$; the NUC is Ethernet (or wireless) controlled by a laptop via a SSH connection, thus making possible to remotely control the XRF scanner from any desired position.

In the LAB-DAQ mode, instead, the digitiser is directly linked to a desktop pc via optical link, which supports transfer rate of $80 \mathrm{MB} / \mathrm{s}$ and offers Daisy-chain capability, but is limited to a maximum distance of $20 \mathrm{~m}$.

In both modes, all the parameters used for data digitisation may be changed in real time. The "oscilloscope" feature, embedded in the digitiser, allows visualising shape and duration of detector signals and thus makes it possible to adjust the digitiser settings to finely tune signal shaping, to achieve optimal energy resolution.

Data analysis programs (peak fit, 3D view, etc.) have been also developed in QT using the CERN_ROOT routines (Root 2018). All the programs are linked with each other via shared memory and can work at the same time on the same dataset. In the following, the main features of our software are shortly described.

\subsubsection{Online map and spectrum}

For each pixel of the map, both the $\mathrm{X}-\mathrm{Y}$ coordinates and the X-ray spectrum, acquired while the stage is travelling inside that pixel, are recorded. In this way, after

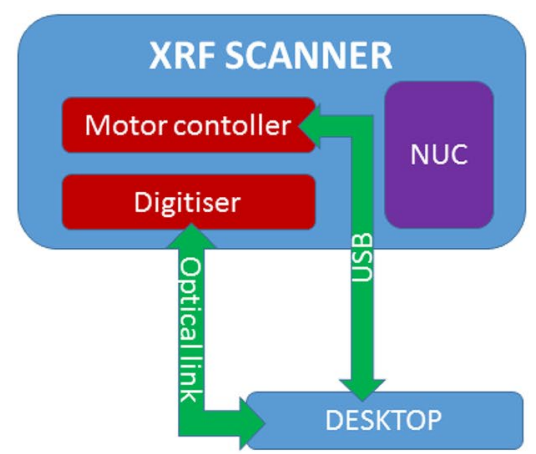

control the XRF scanner from any desired position. In the LAB-DAQ mode, instead, the digitiser is directly linked to a desktop pc via optical link, which allows for faster data transfer but is limited to a maximum distance of $20 \mathrm{~m}$ 
measurement completion, all the pieces of information collected over the total area are rearranged in such a way as to obtain:

- The spatial distribution map of the collected X-rays (by choosing energy regions of interest).

- The total spectrum of the X-rays acquired all over the scanned area.
An example of the above-mentioned features is reported in Fig. 3, where the results obtained after the scan of an illuminated capital letter "E" of a medieval antiphonary, previously studied in (Bussotti et al. 1997), are shown.

To provide elements for online interpretation of the studied sample, the online spectrum and up to four maps (corresponding to diverse elements/energy-windows selected before starting the measurement) can be displayed. The pixel size can be defined by the user at the beginning of the
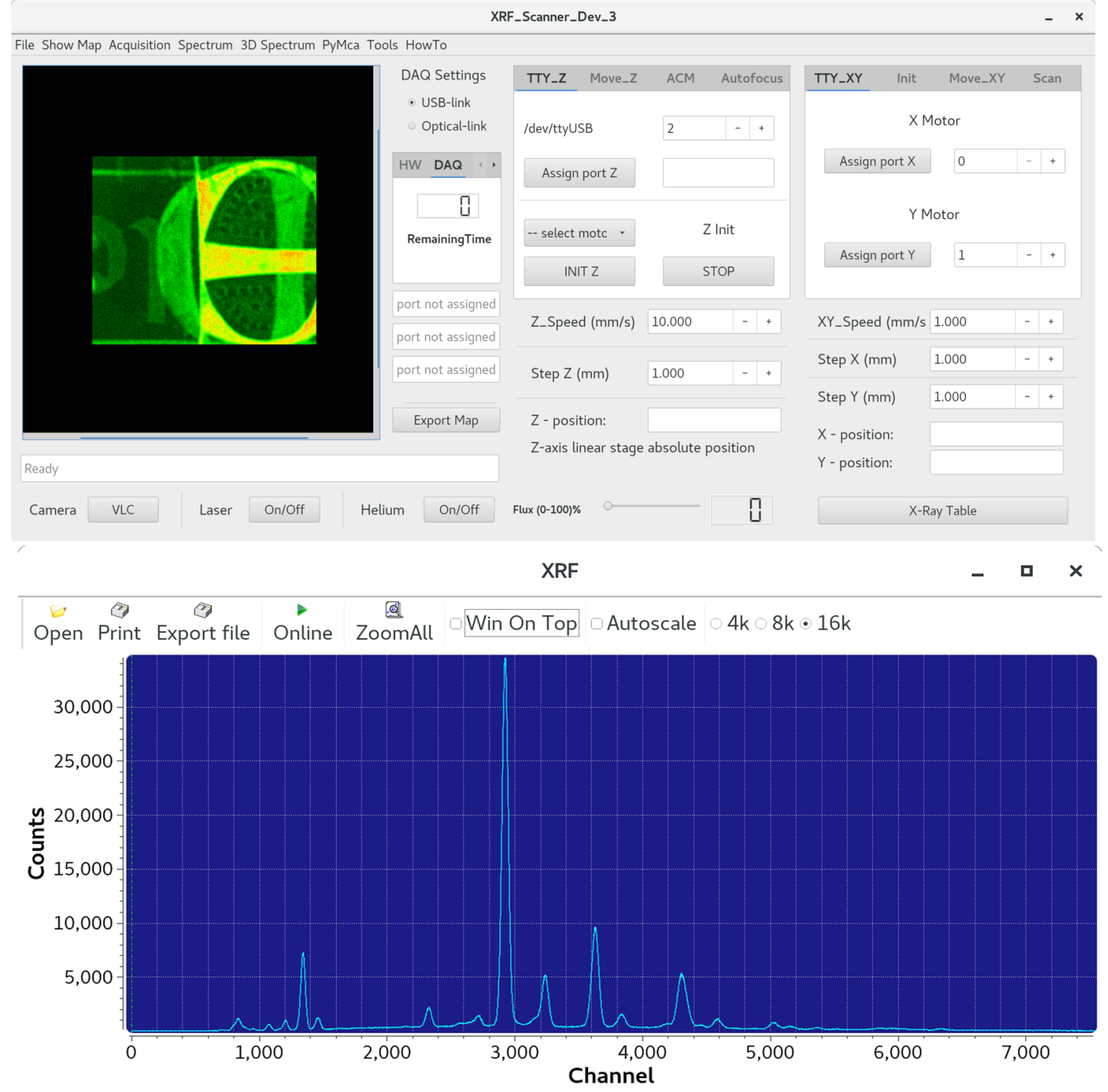

DAQ and Calibration

$\square$ Channel/Energy LogScale keV/Ch $\nabla \nabla 1$

Fig. 3 (Top) Map of the spatial distribution of the X-rays intensity and (bottom) spectrum of all the detected X-rays, obtained after a scan of an illuminated capital letter "E" of a medieval antiphonary. The sample studied in this measurement is a non-flat sample and all the three motors have been used, $\mathrm{X}$ and $\mathrm{Y}$ for scanning the surface

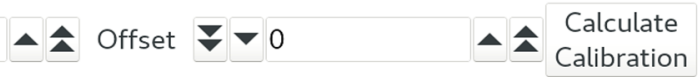

and $\mathrm{Z}$ to keep the sample-to-scanner distance constant (it can be seen in the right part of the top picture that all the three motors were active (labels are black and not grey) and assigned to three different USB ports 
measurement to decide map statistics and spatial resolution (see Sect. 3.5 for details).

\subsubsection{Offline data analysis}

When acquired data are reloaded for offline data analysis, the map of the total scanned area (hereinafter referred to as the "integral map") is automatically displayed. At this point, any energy-interval/element in the spectrum may be selected and the corresponding map displayed and saved. When the integral map is loaded, by mouse clicking on any pixel of the map, the spectrum acquired on that pixel can be displayed on the spectrum viewer. Analogously, when an area is dragged on any portion of the integral map, the spectrum acquired on the area corresponding to the selected area is shown. On the spectrum, it is possible to extract peak area and Full Width at Half Maximum (FWHM), for single and multiple peaks, by exploiting the "fit" tool, which fits the selected peaks with Gaussian shapes and gives back areas, FWHMs and background (available background: constant, linear...).

\subsubsection{D tool}

Since 2D maps do not explicitly show the bin contents (i.e. their statistical significance), to make the statistical information of every pixel more easily readable, an interactive "3D tool" (based on ROOT CERN software) has been developed, which, at a glance, shows the statistical content of each pixel of the loaded map. An example of the results obtainable with this tool is shown in Fig. 4.

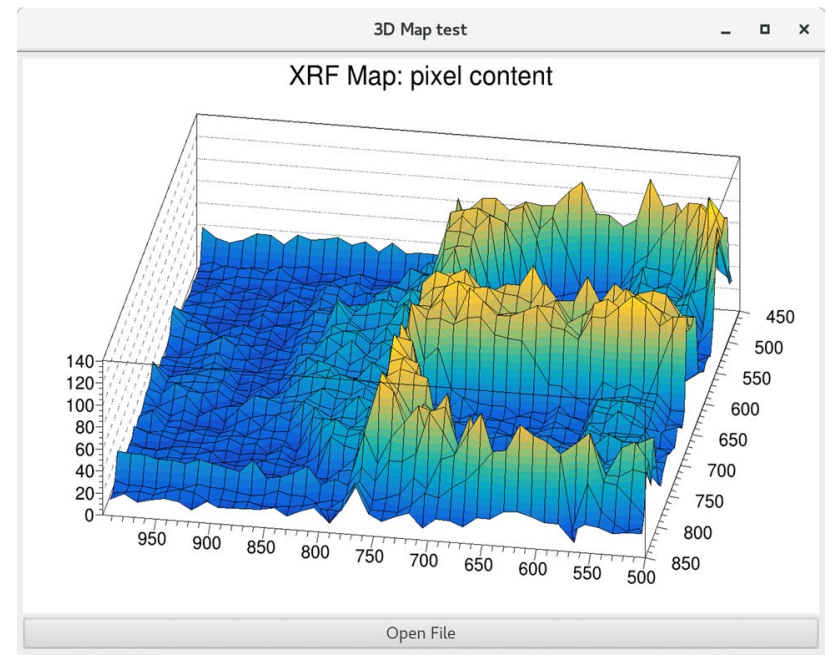

Fig. 4 An example of results produced by the 3D tool: the figure shows the spatial distribution of the number of counts in every pixel of the loaded map (Cu). $X$ and $Y$ : spatial coordinates of the pixel of the map; $Z=N$ counts $(X, Y)$ : number of counts as a function of the $X$, $Y$ pixel coordinates. The scanned area corresponds to the capital letter of the previous figure
For the selected element (or energy gate), the map allows evaluating at a glance the number of counts in the pixels of the background, where the element of interest is absent (dark blue), in the transition regions (azure-turquoise) and where the element has the highest concentration (yellow). As the map provides the statistical content of each pixel, it gives a valuable hint to decide whether the acquisition time had been sufficient or not.

\subsubsection{RGB tool}

As the user selects three elements of interest, the RGB tool assigns red, green and blue colours to each of them and combine them in a false colour map, as shown in Fig. 5. It is a crucial tool for pointing out possible correlations among elements in the same area (Solé et al. 2007).

The simultaneous presence of $\mathrm{Hg}$ (red) and Sn (blue) in the same area is clearly evidenced by the pink coloration which indicates the use of a composite material. In this particular case, the simultaneous presence of $\mathrm{Hg}$ and $\mathrm{Sn}$ in the gilded areas suggests the use of Purpurin or Mosaic gold, one of the most important gold surrogates. The use of Purpurin in a medieval antiphonary points out the use of restoration material. The use of the RGB tool is a way of presenting the obtained results which noticeably enhances the readability for non-trained personnel.

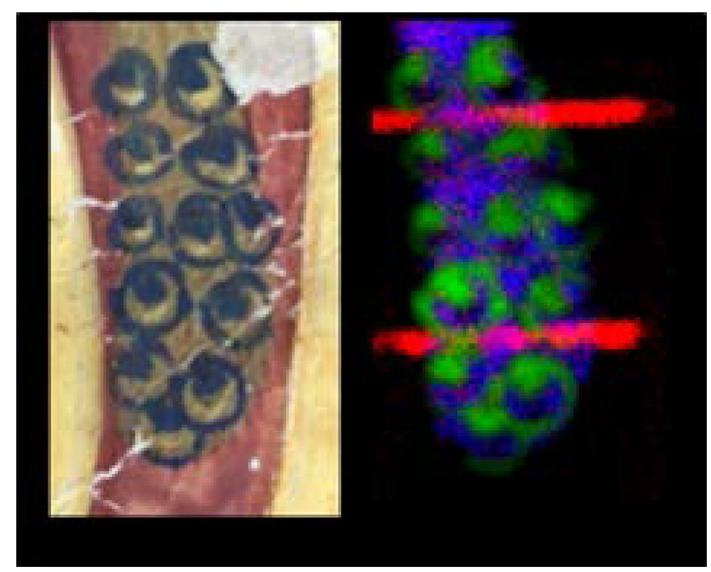

Fig. 5 An example of a false colour map, obtained using the RGB tool. In this example, red, green and blue colours have been assigned to $\mathrm{Hg}, \mathrm{Cu}$ and $\mathrm{Sn}$, respectively. The scanned area is a portion of a decoration of the same antiphonary of Fig. 3. The simultaneous presence of $\mathrm{Sn}$ (blue) and $\mathrm{Hg}$ (red) is clearly pointed out by the presence of pink spots throughout the area, thus suggesting the use of purpurin, an artificial gold. It may be interesting to note that the red $(\mathrm{Hg})$ stripes in the false colour map, which do not correspond to any visible feature in the optical image, are due to lines in the rear side of the page, drawn with cinnabar ( $\mathrm{HgS})$ (colour figure online) 


\subsection{Characterization}

To characterise the system, extensive measurements have been performed. The main results are reported in the following paragraph.

\subsection{Energy resolution (ER)}

Operating with the digitiser parameters (such as, for example, the trigger threshold or the shaping parameters of the digitised signal), it is possible to optimise the ER by limiting noise contributions. We have tested diverse parameter configurations to obtain the best possible ER for the used detector. ER has been measured to evaluate possible energy resolution dependence on noise contributions from our system (HV detector power supply, scanning motor power supplies, motor controllers, etc.). Measurements have been carried out in three configurations:

- In single spot mode, with the original Amptek power supply, data acquisition hardware and software. No other electronic device was present or in use during this measurement. This is the reference configuration, expected to give the best ER;

- With our acquisition, in single-spot mode, with the digitizer powering the detector and collecting data, still without any other device connected or active. This has allowed evaluating possible ER worsening due just to the acquisitions system of the spectrometer, without any contribution due to motors and related devices;
- With our acquisition, in scanning mode.

The ER has maintained the same value (140 eV@Mn k $\alpha$ line) when passing from the Amptek to our acquisition (both in point and in scanning mode), thus proving the good performances of our acquisition. The result of the acquisition in scanning mode is shown in Fig. 6.

\subsubsection{Detection efficiency (DE)}

Experimental conditions: Mo anode tube, $0.8 \mathrm{~mm}$ collimator (the most typical choice for our measurements), $26 \mathrm{kV}$ anode voltage, $0.1 \mathrm{~mA}$ anode current, $400 \mathrm{~s}$ measuring time, sample-to-exit-snout distance $5.5 \mathrm{~mm}$ (the working distance), which corresponds to a distance between the beam impact point on sample and the detector Be entrance window of $\sim 25 \mathrm{~mm}$ (standard measurement geometry). For enhancing low-energy X-ray transmission, He atmosphere has been used between sample and detector, both along the primary (from tube to sample) and secondary (from sample to detector) X-ray paths. The scan mode $\left(1 \times 1 \mathrm{~cm}^{2}\right)$ has been adopted to prevent the risk of measuring in non-representative points.

Measurements were carried out on thin $\left(\sim 50 \mu \mathrm{g} / \mathrm{cm}^{2}\right)$ mono/bi-elemental standards by Micromatter Inc. The DEs for the $K$ and $L$ lines are reported in Fig. 7.

In Fig. 7, the DE is expressed as the area of the main peak of the $K_{\alpha 1}$ lines, normalised to the acquisition time, the anode current and the thickness of the target material (in $\mu \mathrm{g} / \mathrm{cm}^{2}$ ). For comparison, also the efficiency
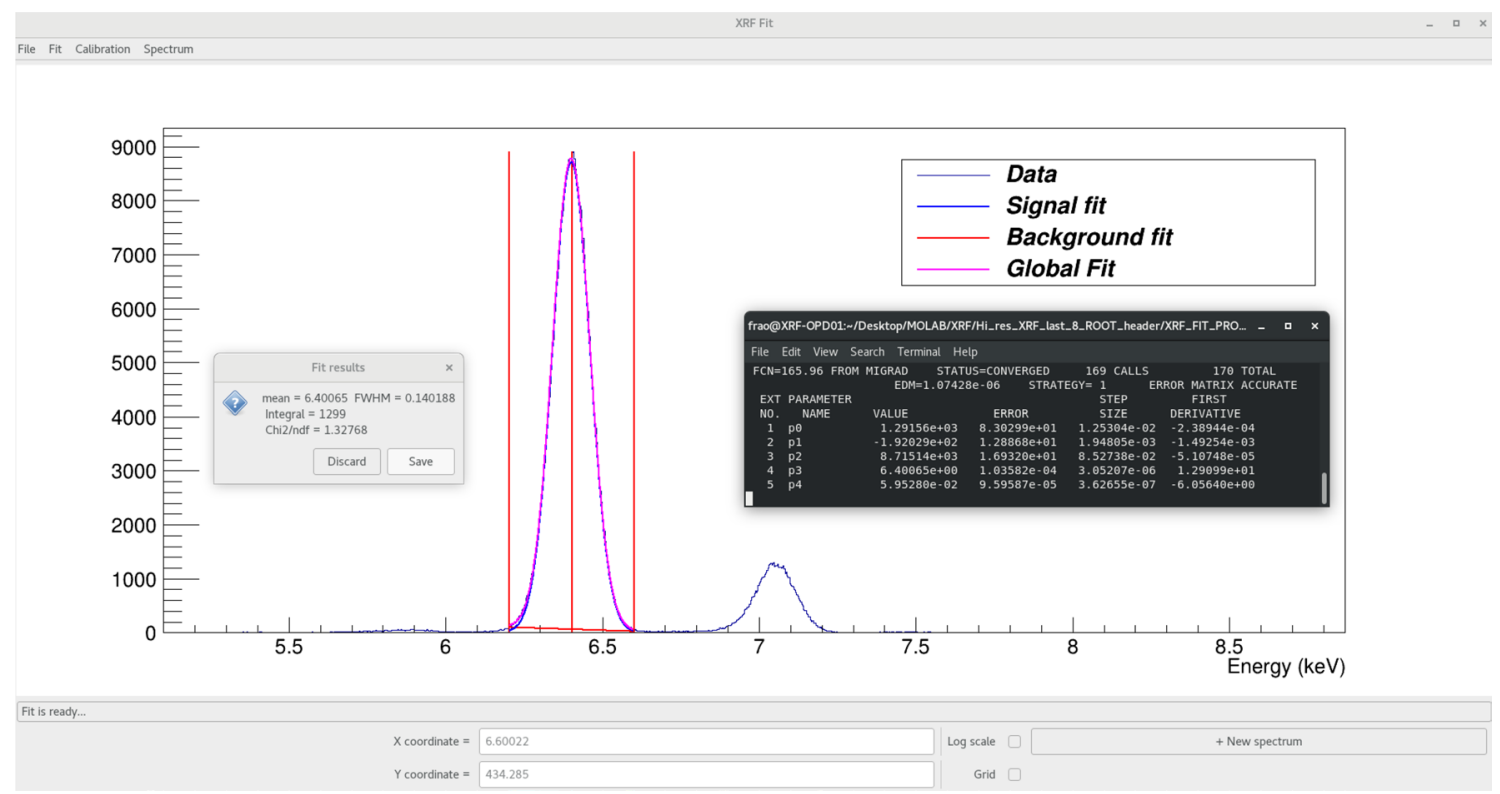

Fig. 6 Use of the Fit Tool, embedded in the acquisition program (see Sect. 2.2), for the measurement of the FWHM of the Mn k $\alpha$ line $(0.140 \mathrm{keV}$ in the "Fit Result" box $)$ 


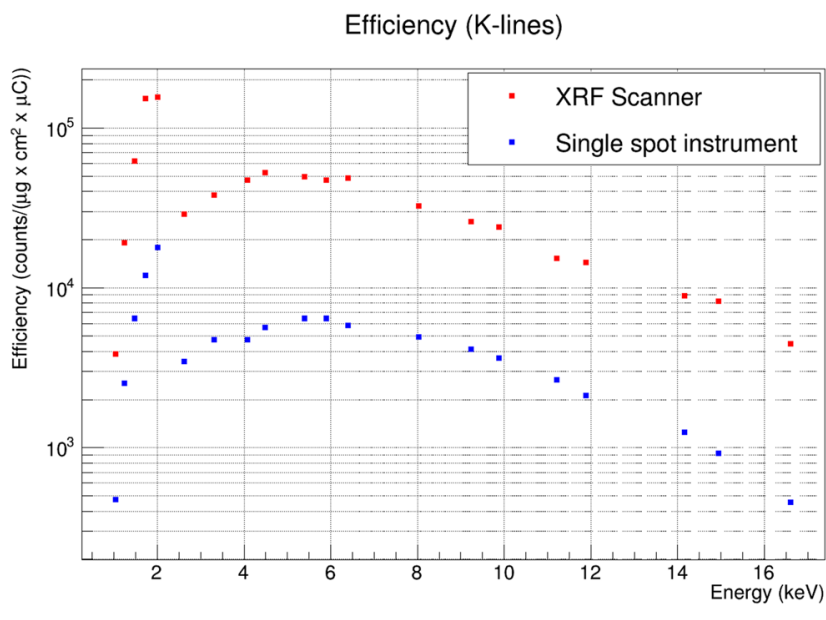

Fig. 7 For every element, the DE of the XRF scanner (red) is expressed as the $K_{\alpha 1}$ line area, normalised to the acquisition time (400 s), the current $(0.1 \mathrm{~mA})$ and the thickness of the target material (in $\mu \mathrm{g} / \mathrm{cm}^{2}$ ). Measurements were carried out at $26 \mathrm{kV}$ anode voltage. For comparison, the DE of our previous single-spot spectrom-

curves of our previous X-ray spectrometer are reported (Migliori et al. 2011). As it can be noted, there is a noticeable ( one order of magnitude) improvement of the DE when passing from the previous to the present set-up. This improvement has been obtained mainly thanks to:

- The improvement of the irradiation geometry. The distance from the sample-to the X-ray tube has been lowered from $120 \mathrm{~mm}$ down to $35 \mathrm{~mm}$, which enhances the transmission of the medium/low X-rays from source to sample;

- The improvement of the detection geometry. The detection solid angle has been increased, as we have now the same sample-to-detector distance, but the detector active area increased from 10 to $50 \mathrm{~mm}^{2}$.

\subsubsection{Minimum detection limits (MDLs)}

MDL have been measured using the SRM 621 thick glass standard (medium-light matrix) (NIST 2018) in the same experimental conditions as in the ER measurements. MDLs are reported in Table 1.

Very good MDL values have been obtained, if compared to most of the commercial instrumentations and even with respect to our previous XRF instrument (Migliori et al. 2011). In particular, it is worth noting that the MDLs are quite good especially for the low-Z elements ( $3 \%$ for $\mathrm{Na}$ ), thanks to the use of $\mathrm{He}$ atmosphere.

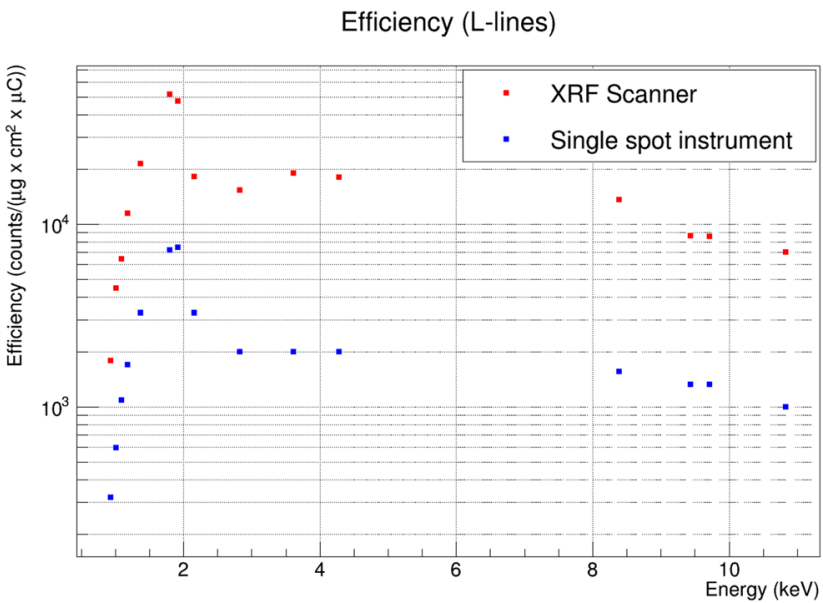

eter (blue) measured with the same anode voltage and using the same anode is also reported (Migliori et al. 2011). The noticeable improvement in DE all over the whole range of detected elements, for both $\mathrm{K}$ and L lines, is apparent (colour figure online)

Table 1 MDL obtained using thick glass standards (medium-light matrix) SRM 621 by NIST, in the same geometry and experimental conditions as in the measurements for DE

\begin{tabular}{lrc}
\hline Element & MDL (ppm) XRF scanner & $\begin{array}{l}\text { MDL (ppm) point- } \\
\text { mode XRF }\end{array}$ \\
\hline $\mathrm{Na}$ & 3000 & 8000 \\
$\mathrm{Si}$ & 34 & 330 \\
$\mathrm{~K}$ & 54 & 120 \\
$\mathrm{Ca}$ & 80 & 60 \\
$\mathrm{Fe}$ & 13 & 20 \\
$\mathrm{As}$ & 8 & 11 \\
\hline
\end{tabular}

For reference, also the MDL obtained with our previous instrument are reported. Notwithstanding the $50 \%$ longer acquisition time $(600 \mathrm{~s}$ with the previous one, $400 \mathrm{~s}$ with the present set-up), our previous instrument generally showed worse MDL (Migliori et al. 2011)

\subsubsection{Beam shape, dimensions and stability in time, spatial resolution}

Beam characteristics have been measured by irradiating a Hamamatsu TDI Camera $(4608 \times 128$ pixels, corresponding to a $221 \mathrm{~mm} \times 6 \mathrm{~mm} \mathrm{X}$-ray sensitive area, $48 \mu \mathrm{m} \times 48 \mu \mathrm{m}$ pixel size, $110 \mu \mathrm{m}$ aluminium filter and $450 \mu \mathrm{m}$ thick CsI scintillator) with our Moxtek MAGNUM tubes. Here, for sake of brevity, we only report on the measurements with the $0.8 \mathrm{~mm}$ collimator.

Due to the geometry of the TDI camera, when the tube collimator is in contact with the camera (minimum possible distance between the two objects), the distance between the CCD and the collimator is $11 \mathrm{~mm}$, 

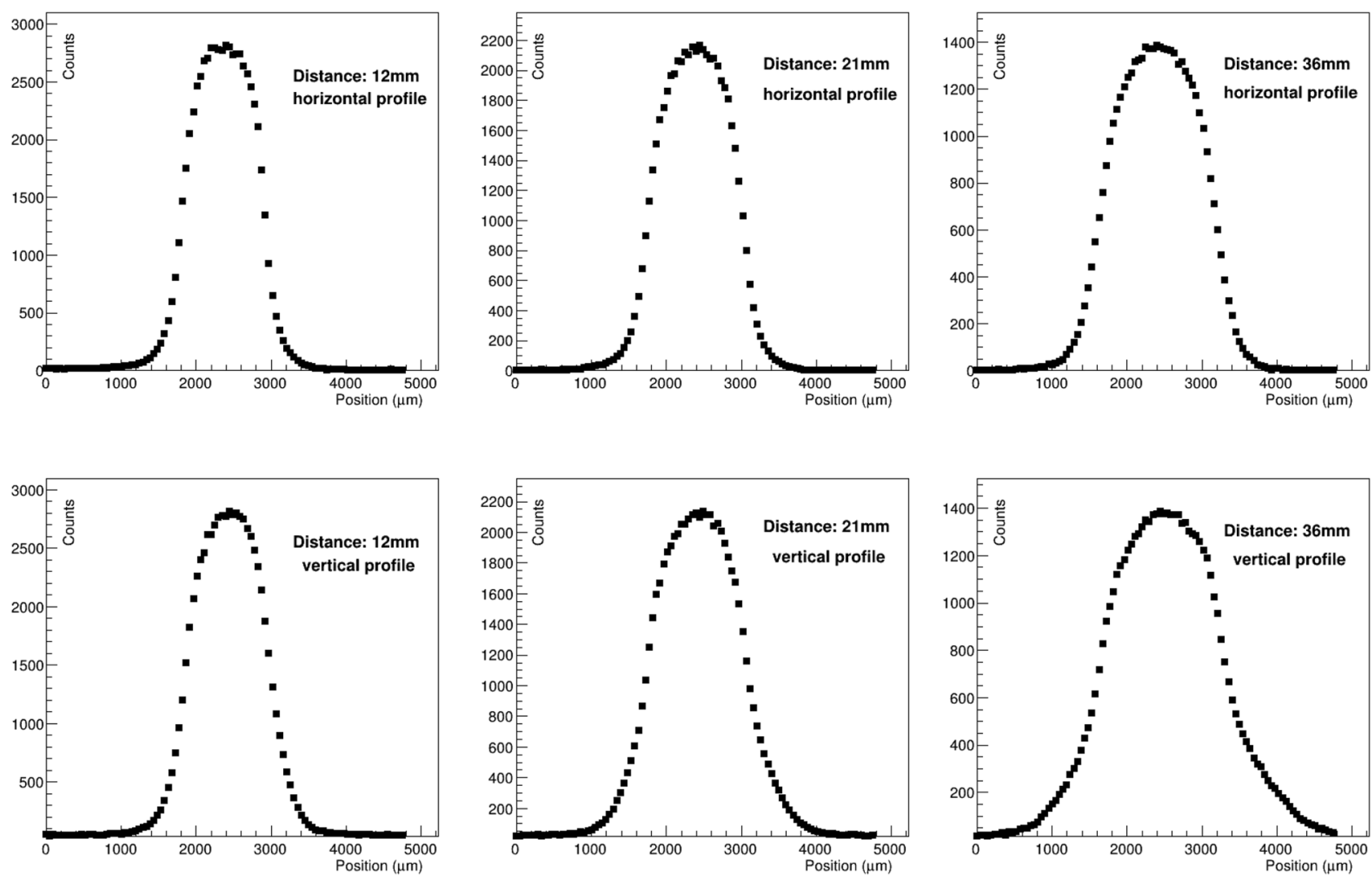

Fig. 8 Horizontal (top) and vertical (bottom) beam profiles at $D_{1}=12 \mathrm{~mm}, D_{3}=21 \mathrm{~mm}$ and $D_{6}=36 \mathrm{~mm}$ distances between tube collimator and CCD. The figures allow also for quantifying the wid-

because of the presence of a protective layer in front of the CCD. Consequently, there is a $11 \mathrm{~mm}$ offset in all the distances at which the beam diameter can be measured $\left(D_{1}=12=11+1 \mathrm{~mm}, D_{2}=16=11+5 \mathrm{~mm}\right.$, $D_{3}=21=11+10 \mathrm{~mm}, D_{4}=26=11+15 \mathrm{~mm}$, $D_{5}=31=11+20 \mathrm{~mm}$ and $\left.D_{6}=36=11+15 \mathrm{~mm}\right)$. The beam profiles at $D_{1}, D_{3}$ and $D_{6}$ are shown in Fig. 8 .

For every distance, the measurement of the beam dimensions has been repeated 100 times, to obtain the relative uncertainty, as shown in Fig. 9 for distance $D_{3}=21 \mathrm{~mm}$, corresponding to beam dimensions $X=1107 \pm 0.4 \mu \mathrm{m}$ and $Y=1301 \pm 0.3 \mu \mathrm{m}$. From these measurements, it has been possible to point out that the beam profile is noticeably regular, a not obvious feature when working with miniaturised X-ray tubes.

From the measurements, it has been possible to point out the excellent stability of the beam dimensions over time, with a few microns associated uncertainty at all distances.

The horizontal and vertical beam dimensions, with uncertainties, have thus been measured for the six distances, which has allowed for determining beam divergence. ening of the beam with distance (see below, Fig. 9 and successive discussion) due to the beam divergence

Figure 10 shows the linear fit of the horizontal and vertical beam dimensions (with the relative uncertainties) as a function of the collimator-to-CCD distance. The linear fit to the data is satisfactory (reduced ${ }^{2} \sim 1$ ), for both $X$ and $Y$ directions, and has allowed for obtaining both the divergence and beam dimensions at the collimator (with uncertainties).

The measured beam divergences (the $\mathrm{p} 1$ coefficient of the linear fits) are $16 \mu \mathrm{m} / \mathrm{mm}$ for the horizontal and $26 \mu \mathrm{m} / \mathrm{mm}$ for the vertical directions, respectively.

At the working distance, the horizontal and vertical beam dimensions, extrapolated with this linear model, resulted to be $875 \mu \mathrm{m}(\mathrm{H})$ and $895 \mu \mathrm{m}(\mathrm{V})$ respectively, of the order of $100 \mu \mathrm{m}$ larger than the beam dimensions at the exit of the collimator $[\sim 780 \mu \mathrm{m}(\mathrm{H})$ and $\sim 750 \mu \mathrm{m}(\mathrm{V})$ respectively, as provided by the $\mathrm{p} 0$ coefficient $]$.

The measured beam divergences (the $\mathrm{p} 1$ coefficient of the linear fits) are $\sim 16 \mu \mathrm{m} / \mathrm{mm}$ for the horizontal and $\sim 26 \mu \mathrm{m} /$ $\mathrm{mm}$ for the vertical directions, respectively. These values show that, thanks to the adoption of the tracking system, which allows for maintaining the sample/to-scanner distance constant within $\pm 0.5 \mathrm{~mm}$, the beam dimension variations, and thus the loss of spatial resolution, are negligible with respect to beam dimensions $(0.8 \mathrm{~mm})$. 
Fig. 9 Distribution of the horizontal (left) and vertical (right) dimensions of the beam profiles measured at one of the six distances $\left(D_{3}=21 \mathrm{~mm}\right.$ collimatorto-CCD distance). For every distance, $\sigma$ has been assumed as the uncertainty on the beam dimensions. For the distance $D_{3}=21 \mathrm{~mm}$, beam dimensions resulted: $X=1107 \pm 3 \mu \mathrm{m}$ and $Y=1301 \pm 3 \mu \mathrm{m}$. The very small $(\sim 3 \mu \mathrm{m})$ show the excellent stability over the time of the beam dimensions
Distribution of FWHM: x projection

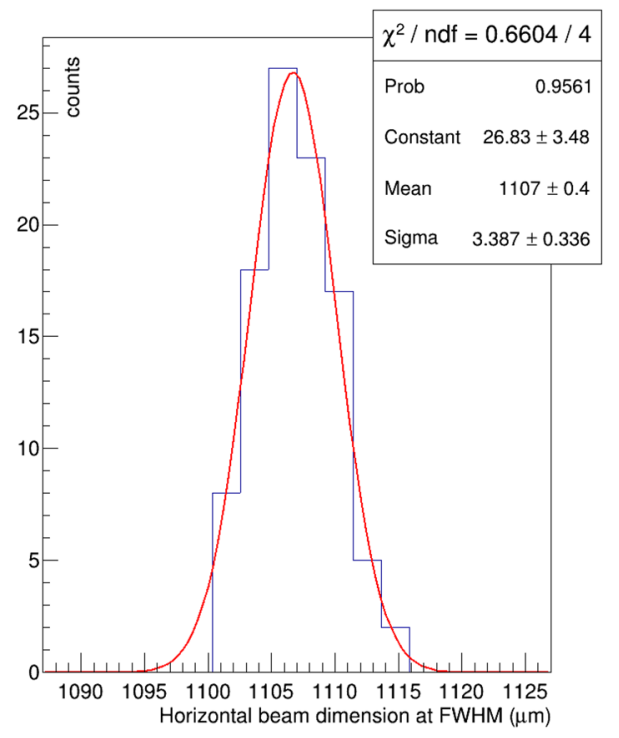

Distribution of FWHM: y projection

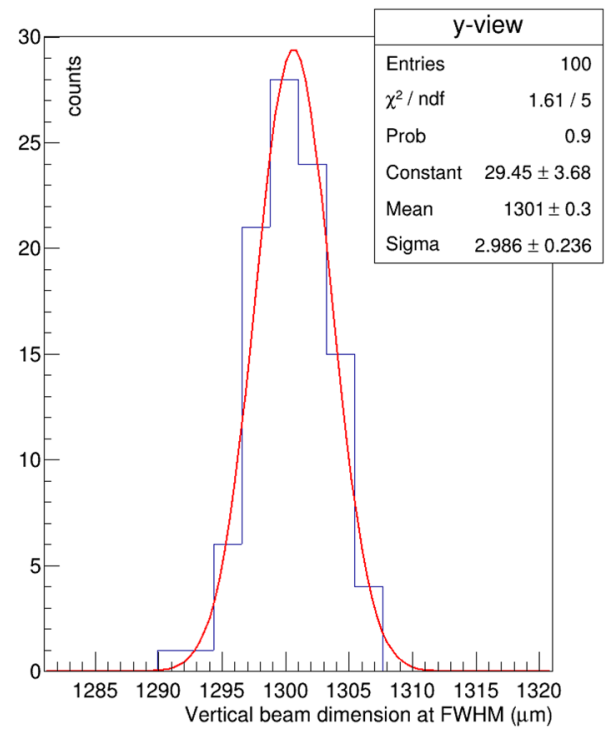

\subsubsection{Mapping: scanning speed, pixel size}

The mapping system has been tested to check the response of the DAQ as a function of the acquisition count rate. Tests have been performed using a DT 5800 CAEN pulser with a repetition rate $v=20 \mathrm{kHz}$, while scanning an area of about $30 \mathrm{~cm}^{2}$, using a $1 \mathrm{~mm}^{2}$ pixel.

In Fig. 11, the distribution of the counts per pixel is reported for the $8 \mathrm{~mm} / \mathrm{s}$ scanning speed. The distribution is quite narrow ( $\sim 3$ channel), evidencing the very good stability of the acquisition system and the constancy of the motor speed over the whole scanned surface; the average value (2495) is just $2 \%$ o (5 counts) lower than the expected nominal value (2500, which would be the expected value for the $: \Delta t=0.125 \mathrm{~s}$ acquisition time in each $1 \mathrm{~mm}$ wide pixel, as $N_{\text {CountsperPixel }}=\Delta t \cdot v$, in absence of any dead time effect).

As $\Delta t$, the time spent over every pixel, is proportional to the scanning speed $\mathrm{v}(\Delta t=x / v$, being $\mathrm{v}$ the scanning speed and $x$ the pixel size), the number of counts per pixel is expected to show a linear dependence on the time spent per pixel, when the rate of input pulses is constant, as in this case. To verify this feature, we have checked the response of our acquisition system versus the scanning speed, which has been varied from 2 to $20 \mathrm{~mm} / \mathrm{s}$ (which corresponds to a variation of the time elapsed on every pixel from 50 to $500 \mathrm{~ms}$ ). In Fig. 12, a summary of the tests of the linearity of the DAQ system vs the scanning speed is reported.
Fig. 10 Linear fit of the horizontal (left) and vertical (right) beam dimensions as a function of the collimatorto-CCD distance. The fit to the data is satisfactory, with reduced $\chi^{2} \sim 1$ for the $X$ and $Y$ directions. The horizontal and vertical beam dimensions at the working distance, extrapolated with this linear model, resulted to be $875 \mu \mathrm{m}(\mathrm{H})$ and $895 \mu \mathrm{m}(\mathrm{V})$ respectively, of the order of $100 \mu \mathrm{m}$ larger than the dimensions at the exit of the collimator, provided by the $\mathrm{p} 0$ coefficient
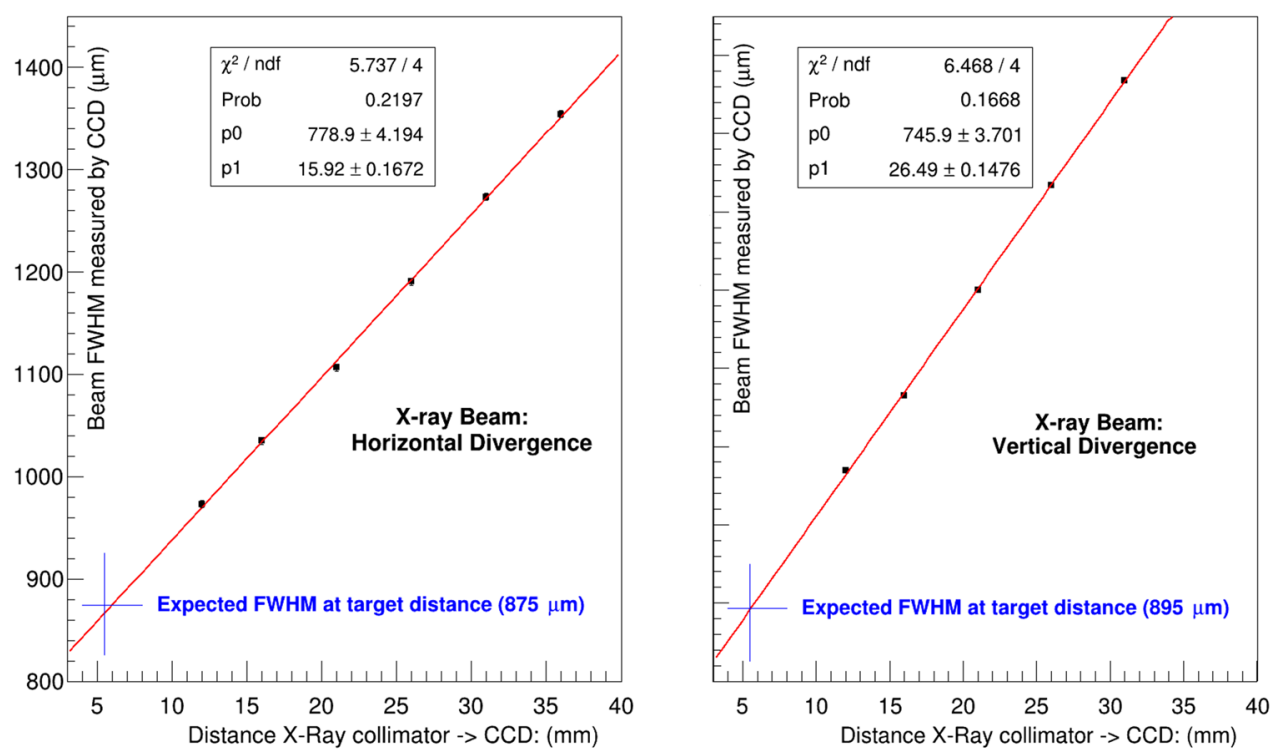
Fig. 11 (Top) Distribution of the counts per pixel is reported for the $8 \mathrm{~mm} / \mathrm{s}$ scanning speed; the average value (2495) is just five units lower than the expected nominal value (2500). The distribution is quite narrow $(\sigma \sim 3)$, which puts into evidence the very good stability of the acquisition system. (bottom) The distribution of the counts per pixel as a function of the pixel is reported. The very good stability of the count rate over the whole surface is apparent

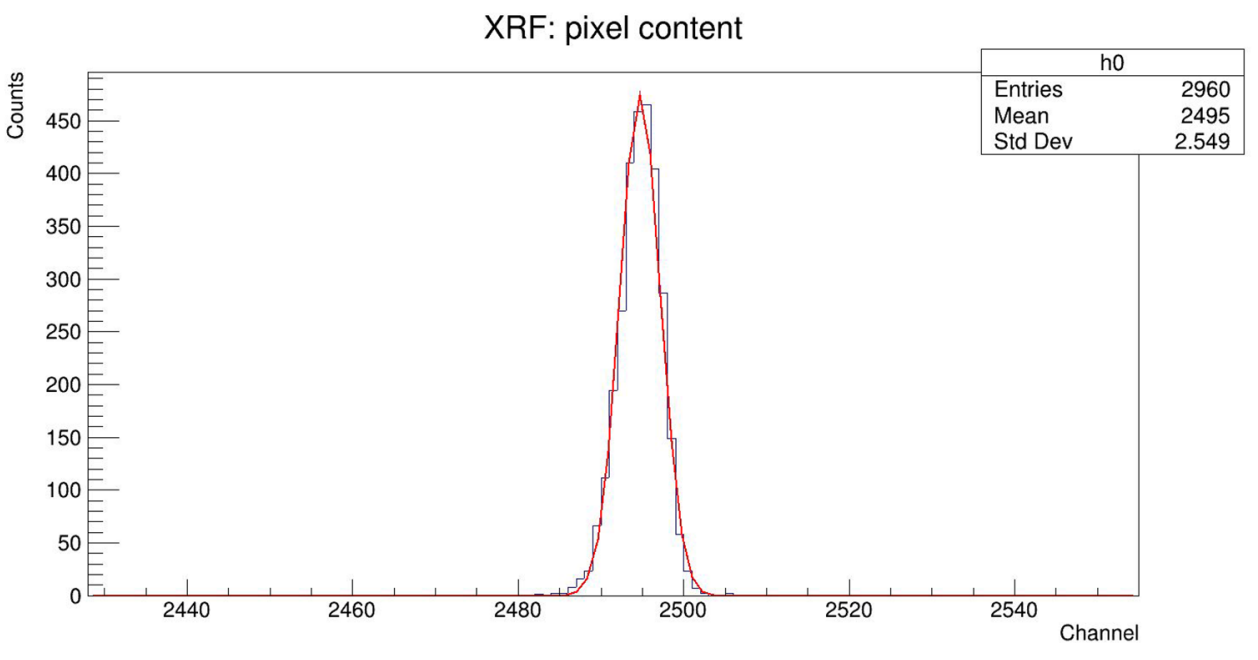

XRF Map: pixel content
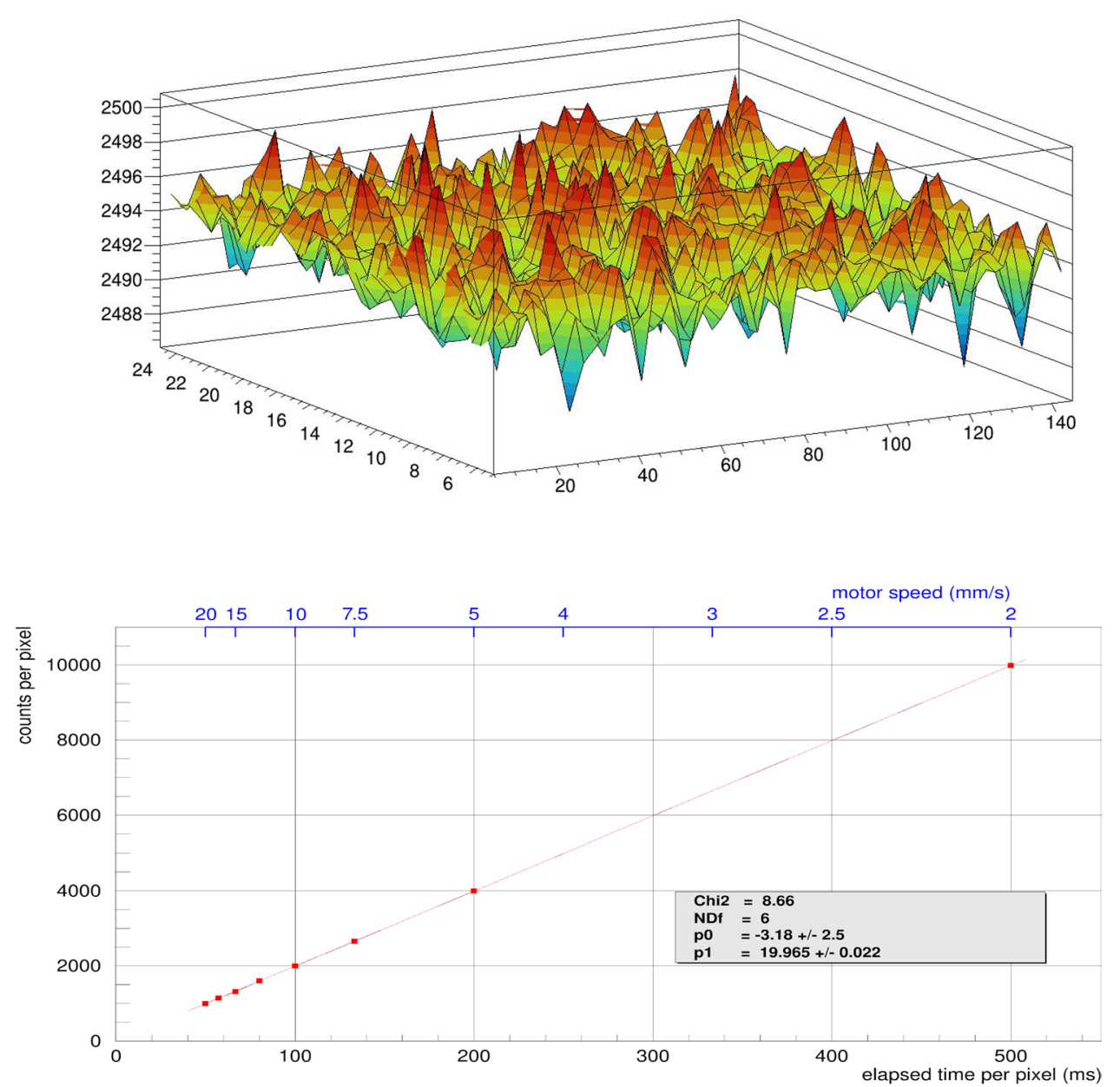

Fig. 12 Number of counts per pixel as a function of the scanning speed. The linear dependence of the number of counts per pixel as a function of the time elapsed per pixel is clearly shown by the reduced $\chi^{2} \sim 1$.

The $\mathrm{p} 0$ and $\mathrm{p} 1$ coefficients, the expected number of counts for a zero elapsed time per pixel and the number of counts per millisecond, respectively, are in good agreement with the expected values ( 0 and 20$)$
The linear dependence of the number of counts per pixel as a function of the time elapsed per pixel is clearly shown by the reduced ${ }^{2} \sim 1$. The $\mathrm{p} 0$ and $\mathrm{p} 1$ coefficients, the expected number of counts for a zero time spent per pixel and the number of counts per millisecond, respectively, are in good agreement with the expected values (0 and 20). The good performance of our acquisition system for a wide range of scanning speed is thus verified.

Finally, as the pixel size is a parameter under full control of the experimenter, and thus can be changed depending on the applications, we conclude with some considerations about the influence of the pixel size on the elemental maps. 


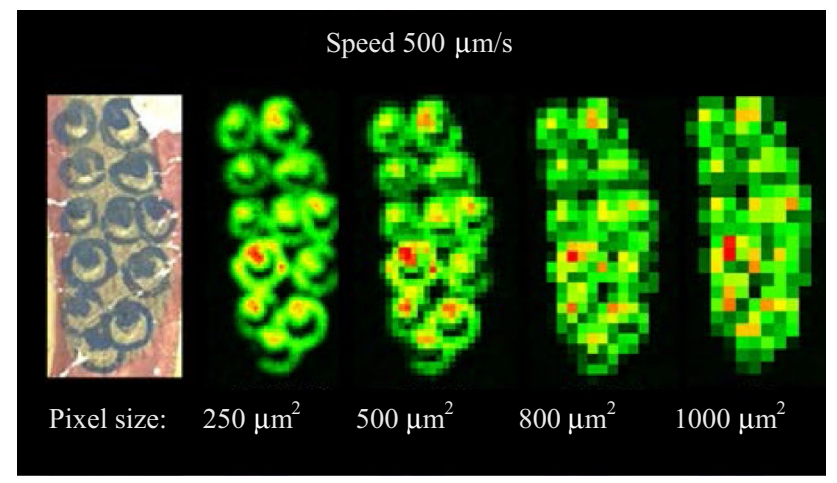

Fig. $13 \mathrm{Cu}$ elemental maps of the same scanned area obtained with a $800 \mu \mathrm{m}$ collimator (scanning speed $500 \mu \mathrm{m} / \mathrm{s}$ ), at different pixel sizes $(250,500,800$ and $1000 \mu \mathrm{m})$. (To be noted that in the showed maps, the colours correspond to different count levels, e.g. the red colour is always used for the maximum number of counts, but at lowest speed, it corresponds to a much higher value than that obtained at the highest speed)

In Fig. 4, we report on the results obtained using the $0.8 \mathrm{~mm}$ collimator and repeating the measurements always in the same experimental conditions but with different pixel sizes $(250,500,800$ and $1000 \mu \mathrm{m})$.

As expected and as can be noted in Fig. 13, decreasing the pixel size, sharper elemental maps are obtained. Indeed, in the map acquired with a pixel size of $250 \mu \mathrm{m}$, the blue copper rings can be clearly distinguished, what is not possible with the larger step dimensions: the smaller the step, the finer the details of the target that the system can resolve, of course always being limited also by the beam dimension. Being the beam spot size on a sample about $800 \mu \mathrm{m}$, lowering the pixel size below 100-200 $\mu \mathrm{m}$ would not produce substantial improvements in the information provided by the maps. Therefore, oversampling, that is scanning with a pixel size smaller than the beam dimension, is typically carried on, but limited to less than a factor 10, as typically (pixel_ size $) \geq$ (beam_size/10), depending on the required accuracy.

\subsubsection{Autofocus}

The autofocus system allows maintaining the sample-toscanner distance at the desired value, i.e. at the working distance. Tests have been carried out to quantify the influence on the number of detected X-rays of the variation of the distance of the XRF head (X-ray source + the X-ray detector, the latter at $45^{\circ}$ with respect to the primary $\mathrm{X}$-ray direction) from the target, with special attention to the region around the working zone $(5.5 \pm 0.5 \mathrm{~mm})$.

Tests have been focused on the variation of the number of counts $N_{\mathrm{c}}\left(N_{\mathrm{c}}=\right.$ area of the Pb L $\alpha+\mathrm{L} \beta$ lines $)$ versus distance. A thick lead target has been exposed to the $\mathrm{X}$-ray beam (the tube was operating always in the same

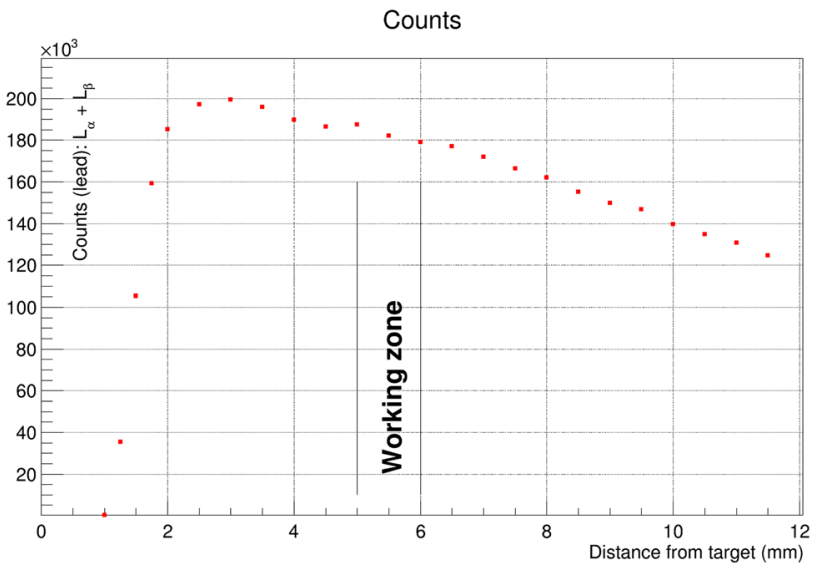

Fig. 14 Study of the variation of the number of counts $N_{\mathrm{c}}$ as a function of the sample-to-scanner distance. A thick lead target has been exposed to X-ray beam (same anode current, voltage and acquisition time) for different values of the sample-to-collimator distance. The total number of counts has then been reported as a function of the distance. For these measurements, the scanner has been moved along the beam axis for values ranging from zero (when the collimator is in contact with the lead block) to $11 \mathrm{~mm}$ (a distance as big as the double of the working distance). When the distance is maintained inside the working zone, no critical dependence of $\mathrm{Nc}$ on the distance has been evidenced

conditions, i.e. same anode current, voltage and acquisition time) for different values of the sample-to-collimator distance. The total number of counts Nc has then been reported as a function of the distance, which has been varied from zero (when the collimator is in contact with the lead block) to $11 \mathrm{~mm}$ (a distance as big as the double of the working distance). Results are reported in Fig. 14.

From Fig. 14, we can see that Nc shows only a slight dependence on the position.

When position variations stay inside the working zone, Nc changes of about $\pm 3 \%$ and is thus normally negligible with respect to experimental errors.

Further increase of the distance corresponds to a further decrease of Nc (of $40 \%$ at $11 \mathrm{~mm}$ ), which, however, never shows a sharp drop. This reduction is mainly due to a bad aiming of the detector to the beam impact point on sample: actually, the primary X-rays always hits the sample in the point $P$, whichever the sample-scanner distance. The aiming line of the detector is directed towards the point $\mathrm{P}$ only when the target-to-collimator distance is the working distance. An additional reason for the decrease of $N_{\mathrm{c}}$ is due to the fact that, when the distance increases, there is also an increase of the absorption in air of the secondary $\mathrm{X}$-rays from target to detector. The solid angle decrease, in the range of studied distances of Fig. 14, has only an effect of few percent.

Reduction of the distance from the working value down to about $3 \mathrm{~mm}$ implies a mild increase of $N_{\mathrm{c}}$ of about $10 \%$, 
Fig. 15 Optical image of the scanned area and the most interesting elemental maps, from low to high energies, acquired with (top row) and without (bottom row) the autofocus system. Most of the decoration lies in correspondence of a "bump" $(\sim 1,2 \mathrm{~cm})$. The lack of counts in the lower part of the maps acquired in bad geometry, due to the lack of the autofocus system, is apparent

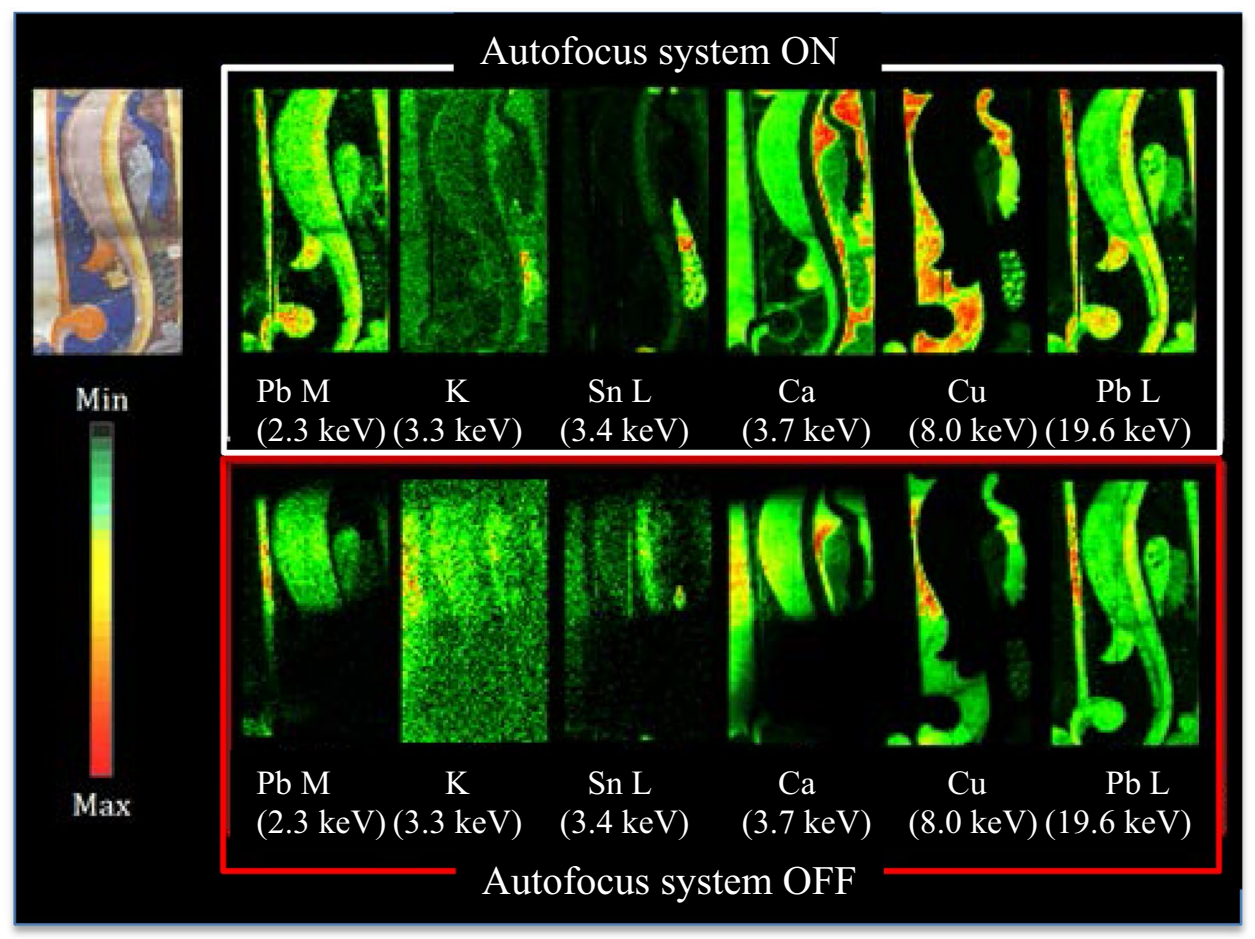

while a further reduction cuts down $N_{\mathrm{c}}$ due to the interference of the nozzle holding the collimator with the detector aiming line.

The effectiveness of the autofocus system can be really appreciated when measuring non-flat samples. In Fig. 15, we report a comparison of the maps acquired on the same undulated surface $(\sim 1.2 \mathrm{~cm}$ difference from top and bottom level) of the already mentioned antiphonary. Top maps have been acquired with the autofocus system, bottom maps without. The extended lack of counts in the region where the scanner was working in bad geometry is apparent and obviously affects more heavily the maps of the low energy $\mathrm{X}$-rays, e.g. the $\mathrm{Pb} \mathrm{M}$ line.

\subsubsection{Radio-safety}

The INFN-CHNet XRF scanner has been designed for use in environments where persons not subjected to radio-safety controls (i.e. everyone who can be catalogued as "normal population", hereafter "the public") can be present. For this reason, we have paid the highest attention to keep X-ray emission as low as possible. As already described, the X-ray tube is enclosed inside a 4-mm thick brass case, a thickness sufficient to completely absorb all the X-rays not passing through the collimator hole, as confirmed by measurements with a Geiger counter. Using a dummy case, exactly as the standard one but without the collimator hole and moving the Geiger counter around the tube, which was working at the maximum voltage and current $(40 \mathrm{kV}$ and $0.1 \mathrm{~mA})$, measurements have shown that no radiation emerges from the brass shield surrounding the X-ray tube (e.g. no radiation is backward emitted towards the operators).

Using the tube at maximum voltage and current and the $0.8 \mathrm{~mm}$ collimator, measurements out of the no-access area have shown that the equivalent dose rate $\dot{H}$ does not differ from the background value $(0.1 \mu \mathrm{Sv} / \mathrm{h})$ and even at $0.7 \mathrm{~m}$ from the beam impact point on sample, the dose equivalent stays extremely low $(\dot{H}<0.2 \mu \mathrm{Sv} / \mathrm{h})$.

On the basis of these results, it has been possible to obtain the official permission of free use for the scanner, even when the public is present, with the only precaution of the adoption of the no-access area. This feature, never reported so far to the best of our knowledge, is crucial for applications in Cultural Heritage.

\subsubsection{Summary and conclusion}

A four-season and green XRF scanner for Cultural Heritage applications has been designed and constructed. It is an innovative instrument as regards its control/acquisition/ analysis software, which have been developed using only open source software.

The INFN-CHNet scanner is a transportable instrument, well suited both for spectroscopy and imaging. It is easy to use and need very low-power to work, a feature which allows it to run on batteries up to $10 \mathrm{~h}$.

Its very low radiation dispersion makes it a perfect instrument to use in any site, especially those where the public is 
present as, out of the $2 \times 2 \mathrm{~m}^{2}$ no-access area, the measured equivalent dose rate does not differ from background.

Our XRF scanner has a very low cost, when compared to commercial systems, which makes it accessible for a much wider portion of the interested community.

This XRF scanner has proved to be really very well suited for applications in the Cultural Heritage field, as testified by the many recent applications. Presently, a fleet of five equivalent instruments distributed all over Italy is ready to move wherever XRF in situ analyses are needed.

The instrument has been thought and designed for further development/improvements, such as multi-detectors or the integration with other analytical techniques and, in general, any feature that can result interesting for non-conventional XRF analysis. First successful tests have already been carried on (Re et al. 2018).

Acknowledgements The authors are deeply indebted to professor Pier Andrea Mandò for the many fruitful discussions, suggestions and indications, which have allowed us to develop a better instrument in a shorter time.

\section{References}

Alfeld M, de Viguerie L (2017) Recent developments in spectroscopic imaging techniques for historical paintings, a review. Spectrochim Acta B 136:81-105. https://doi.org/10.1016/j.sab.2017.08.003

Alfeld M, Pedroso JV, van Eikema Hommes M, Van der Snickt G, Tauber G, Blaas J, Haschke M, Erler K, Dik J, Janssens K (2013a) A mobile instrument for in situ scanning macro-XRF investigation of historical paintings. J Anal At Spectrom 28:760. https://doi. org/10.1039/C3JA30341A

Alfeld M, Van der Snickt G, Vanmeert F, Janssens K, Dik J, Appel K, van der Loeff L, Chavannes M, Meedendorp T, Hendriks E (2013b) Scanning XRF investigation of a flower still life and its underlying composition from the collection of the Kröller-Müller Museum. Appl Phys A 111:165-175. https://doi.org/10.1007/ s00339-012-7526-x

Amptek (2018) http://amptek.com/products/70-mm2-fast-sdd/\#4. Accessed Oct 2018

Bogovac M, Jakšić M, Wegrzynek D, Markowicz A (2009) Digital pulse processor for ion beam microprobe tomography. Nucl Instrum Methods Phys Res A 608:157-162. https://doi. org/10.1016/j.nima.2009.04.049

Bussotti L, Carboncini MP, Castellucci E, Giuntini L, Manđò PA (1997) Identification of pigments in a fourteenth-century miniature by combined micro-Raman and PIXE spectroscopic techniques. Stud Conserv 42:83-92. https://doi.org/10.1179/ sic. 1997.42.2.83

Caen (2018) http://www.caen.it/csite/CaenProd.jsp?parent=64\&idmod =756. Accessed Oct 2018

Charlton MF (2013) Handheld XRF for art and archaeology (Studies in Archaeological Sciences). J Archaeol Sci 40:3058-3059. https ://doi.org/10.1016/j.jas.2013.03.001

Dal Bianco B, Russo U (2012) Basilica of San Marco (Venice, Italy/ Byzantine period): nondestructive investigation on the glass Mosaic Tesserae. J Non Cryst Solids 358:368-378. https://doi. org/10.1016/j.jnoncrysol.2011.10.006

De Keyser N, Van der Snickt G, Van Loon A, Legrand S, Wallert AE, Janssens K (2017) Jan Davidsz de Heem (1606-1684): a technical examination of fruit and flower still-lives combining MA-XRF scanning, cross-section analysis and technical historical sources. Herit Sci 5(1):38. https://doi.org/10.1186/s40494-017-0151-4

Duran A, López-Montes A, Castaing J, Espejo T (2014) Analysis of a royal 15th century illuminated parchment using a portable XRF-XRD system and micro-invasive techniques. J Archaeol Sci 45:52-58. https://doi.org/10.1016/j.jas.2014.02.011

Elisabeth U, Fittschen A, Falkenberg G (2011) Trends in environmental science using microscopic X-ray fluorescence. Spectrochim Acta B 66:567-580. https://doi.org/10.1016/j.sab.2011.06.006

Hoffmann P, Flege S, Ensinger W, Wolf F, Weber C, Seeberg S, Sander J, Schultz J, Krekel C, Tagle R, Wittkopp A (2018) MA-XRF investigation of the Altenberg Retable from 1330. X-Ray Spectrom 47:215-222. https://doi.org/10.1002/xrs.2829

Holakooei P, Soldi S, de Lapérouse J-F, Carò F (2017) Glaze composition of the Iron Age glazed ceramics from Nimrud, Hasanlu and Borsippa preserved at The Metropolitan Museum of Art. J Archaeol Sci Rep 16:224-232. https://doi.org/10.1016/j.jasre p.2017.09.031

Keynce (2018) https://www.keyence.com/products/sensor/positioning/ ia/models/ia-100/index.jsp. Accessed Oct 2018

Lazic V, Vadrucci M, Fantoni R, Chiari M, Mazzinghi A, Gorghinian A (2018) Applications of laser induced breakdown spectroscopy for cultural heritage: a comparison with XRF and PIXE techniques. Spectrochim Acta B At Spectrosc 149:1-14. https://doi. org/10.1016/j.sab.2018.07.012

Legrand S, Ricciardi P, Nodari L, Janssens K (2018) Non-invasive analysis of a 15th century illuminated manuscript fragment: pointbased vs imaging spectroscopy. Microchem J 138:162-172. https ://doi.org/10.1016/j.microc.2018.01.001

Lemière B (2018) A review of pXRF (field portable X-ray fluorescence) applications for applied geochemistry. J Geochem Explor 188:350-363. https://doi.org/10.1016/j.envpol.2016.03.055

Macková A (2016) XRF imaging. In: Macková A, MacGregor D, Azaiez F, Nyberg J, Piasetzky E (eds) Nuclear physics for cultural heritage. Nuclear Physics Division of the European Physical Society, New York, pp 50-53. https://doi. org/10.1071/978-2-7598-2091-7

Mendoza A, Gravie CHP (2011) Portable energy dispersive X-ray fluorescence and X-ray diffraction and radiography system for archaeometry. Nucl Instrum Methods Phys Res A 633:72-78. https://doi. org/10.1016/j.nima.2010.12.178

Migliori A, Bonanni P, Carraresi L, Grassi N, Mandò PA (2011) A novel portable XRF spectrometer with range of detection extended to low-Z elements. X-Ray Spectrom 40:107-112. https://doi. org/10.1002/xrs.1316

Moxtek (2018). http://moxtek.com/wp-content/uploads/pdfs/TUBDATA-1001-TUB00046-Rev-C.pdf. Accessed Oct 2018

NIST (2018). https://www-s.nist.gov/srmors/. Accessed Oct 2018

PI (2018a). https://www.physikinstrumente.com/en/products/linea r-stages/stages-with-stepper-dc-brushless-dc-bldc-motors/vt80-linear-stage-1206300/\#specification. Accessed Oct 2018

PI (2018b)_1. https://www.physikinstrumente.com/en/products/linea r-stages/stages-with-stepper-dc-brushless-dc-bldc-motors/m-404precision-translation-stage-701751/\#specification. Accessed Oct 2018

Profe J, Wach L, Frechen M,Ohlendorf C, Zolitschka B (2018) XRF scanning of discrete samples - A chemostratigraphic approach exemplified for loess-paleosol sequences from the Island of Susak, Croatia, Quaternary International, Available online 16 May 2018, In Press, Corrected Proof, Quaternary International. https://doi. org/10.1016/j.quaint.2018.05.006

QT (2018). https://www.qt.io/developers/. Accessed Oct 2018

Re A, Zangirolami M, Angelici D, Borghi A, Costa E, Giustetto R, Gallo LM, Castelli L, Mazzinghi A, Ruberto C, Taccetti F, Lo Giudice A (2018) Towards a portable X-ray luminescence 
instrument for applications in the cultural heritage field. Eur Phys J Plus 133(9):362. https://doi.org/10.1140/epjp/i2018-12222-8

Ricciardi P, Legrand S, Bertolotti G, Janssens K (2016) Macro X-ray fluorescence (MA-XRF) scanning of illuminated manuscript fragments: potentialities and challenges. Microchem J 124:785-791. https://doi.org/10.1016/j.microc.2015.10.020

Robinson D, Baker MJ, Bedford C, Perry J, Wienhold M, Bernard J, Reeves D, Kotoula E, Gandy D, Miles J (2015) Methodological considerations of integrating portable digital technologies in the analysis and management of complex superimposed Californian pictographs: from spectroscopy and spectral imaging to 3-D scanning. Digit Appl Archaeol Cultural Herit 2:166-180. https://doi. org/10.1016/j.daach.2015.06.001

Romano FP, Caliri C, Cosentino L, Gammino S, Mascali D, Pappalardo L, Rizzo F, Scharf O (2016) Micro X-ray fluorescence imaging in a tabletop full field-X-ray fluorescence instrument and in a full field-particle induced X-ray emission end station. Anal Chem 88:9873-9880. https://doi.org/10.1021/acs.analchem.6b02811

Romano FP, Caliri C, Nicotra P, Di Martino S, Pappalardo L, Rizzo F, Santos HC (2017) Real-time elemental imaging of large dimension paintings with a novel mobile macro X-ray fluorescence (MA-XRF) scanning technique. J Anal At Spectrom 32:773-781. https://doi.org/10.1039/c6ja00439c

Root (2018). https://root.cern.ch/. Accessed Oct 2018

Ruberto CC, Mazzinghi A, Massi M, Castelli L, Czelusniak C, Palla L, Gelli N, Betuzzi M, Impallaria A, Brancaccio R, Peccenini E, Raffaelli M (2016) Imaging study of Raffaello's "La Muta" by a portable XRF spectrometer. Microchem J 126:63-69. https://doi. org/10.1071/978-2-7598-2091-710.1016/j.microc.2015.11.037

Ryan JG, Shervais JW, Li Y, Reagand MK, Li HY, Heaton D, Godard M, Kirchenbaur M, Whattam SA, Pearce JA, Chapman T, Nelson W, Prytulak J, Shimizu K, Petronotis K (2017) the IODP Expedition 352 Scientific Team1, Application of a handheld X-ray fluorescence spectrometer for real-time, high-density quantitative analysis of drilled igneous rocks and sediments during IODP Expedition 352. Chem Geol 451:55-66. https://doi.org/10.1016/j.chemgeo.2017.01.007

Santos C, Caliri C, Pappalardo L, Catalano R, Orlando A, Rizzo F, Romano FP (2016) Identification of forgeries in historical enamels by combining the non-destructive scanning XRF imaging and alpha-PIXE portable techniques. Microchem J 124:241-246. https ://doi.org/10.1016/j.microc.2015.08.025

Solé VA, Papillon E, Cotte M, Walter Ph, Susini J (2007) A multiplatform code for the analysis of energy-dispersive $\mathrm{X}$-ray fluorescence spectra. Spectrochim Acta B 62:63-68. https://doi.org/10.1016/j. sab.2006.12.002

Striova J, Ruberto C, Barucci M, Blažek J, Kuzman D, Dal Fovo A, Pampaloni E, Fontana R (2018) Spectral imaging and archival data in analyzing the Madonna of the Rabbit painting by Manet and Titian. Angew Chem Int 57:7408-7412. https://doi. org/10.1002/anie.201800624

Theden-Ringl F, Gadd P (2017) The application of X-ray fluorescence core scanning in multi-element analyses of a stratified archaeological cave deposit at Wee Jasper, Australia. J Archaeol Sci Rep 14:241-251. https://doi.org/10.1016/j.jasrep.2017.05.038

Van der Snickt G, Dubois H, Sanyova J, Legrand S, Coudray A, Glaude C, Postec M, Van Espen P, Janssens K (2017) Large-area elemental imaging reveals van eyck's original paint layers on the Ghent Altarpiece (1432), rescoping its conservation treatment. Angew Chem Int Edit 56(17):4797-4801. https://doi.org/10.1002/ anie. 201700707

Van der Snickt G, LegrandaIn S, Van Zuien SE, Gruber G, Van der Stighelen K, Klaassen L, Oberthal E, Janssens K (2018) In situ macro $\mathrm{X}$-ray fluorescence (MA-XRF) scanning as a non-invasive tool to probe for subsurface modifications in paintings by PP Rubens. Microchem J 138:238-245. https://doi.org/10.1016/j.microc.2018.01.019

Wegrzynek D, Markowicz A, Bamford S, Chinea-Cano E, Bogovac M (2005) Micro-beam X-ray fluorescence and absorption imaging techniques at the IAEA laboratories. Nucl Instrum Methods Phys Res B 231:176-182. https://doi.org/10.1016/j.nimb.2005.01.053

Wrobel P, Czyzycki M, Furman L, Kolasinski K, Lankosz M, Mrenca A, Samek L, Wegrzynek D (2012) LabVIEW control software for scanning micro-beam X-ray fluorescence spectrometer. Talanta 93:186-192. https://doi.org/10.1016/j.talanta.2012.02.010

Wrobel PM, Bogovac M, Sghaier H, Leani JJ, Migliori A, Padilla-Alvarez R, Czyzycki M, Osan J, Kaiser RB, Karydas AG (2016) LabVIEW interface with Tango control system for a multi-technique $\mathrm{X}$-ray spectrometry IAEA beamline end-station at Elettra Sincrotrone Trieste. Nucl Instrum Methods Phys Res A 833:105-109. https://doi.org/10.1016/j.nima.2016.07.030

Publisher's Note Springer Nature remains neutral with regard to jurisdictional claims in published maps and institutional affiliations.

\section{Affiliations}

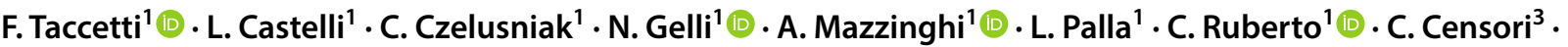

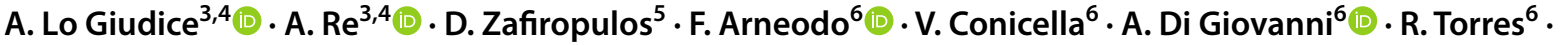 F. Castella $\cdot$ N. Mastrangelo ${ }^{7} \cdot$ D. Gallegos ${ }^{7} \cdot$ M. Tascon ${ }^{7}$ (i) $\cdot$ F. Marte ${ }^{7} \cdot$ L. Giuntini ${ }^{1,2}$ (I)}

L. Giuntini

giuntini@fi.infn.it

1 Istituto Nazionale di Fisica Nucleare (INFN), Sezione di Firenze, Via G. Sansone 1, Sesto Fiorentino, I-50019 Florence, Italy

2 Dipartimento di Fisica e Astronomia, Università di Firenze, Via G. Sansone 1, Sesto Fiorentino, I-50019 Florence, Italy

3 Istituto Nazionale di Fisica Nucleare (INFN), Sezione di Torino, Via P. Giuria 1, 10125 Turin, Italy

4 Dipartimento di Fisica, Università di Torino, Via P. Giuria 1, 10125 Turin, Italy
5 Laboratori Nazionali di Legnaro, Istituto Nazionale di Fisica Nucleare, Viale Dell'Università, 2, Legnaro, 35020 Padua, Italy

6 New York University Abu Dhabi, Abu Dhabi, United Arab Emirates

7 Instituto de Investigaciones Sobre El Patrimonio Cultural, Universidad Nacional de San Martín, B, Quinquela Martín, 1784, San Martín, Ciudad de Buenos Aires, Argentina 